\title{
EFFICACY OF MIPRAGOSIDE OPHTHALMIC GEL IN VERNAL KERATOCONJUNCTIVITIS
}

\author{
MARCO CENTOFANTI ${ }^{1}$, MAURO SCHIAVONE ${ }^{1}$, ALESSANDRO LAMBIASE ${ }^{1}$, \\ MONICA TAFFARA ${ }^{2}$, SEBASTIANO GIUFFRIDA ${ }^{2}$ and STEFANO BONINI ${ }^{1}$ \\ Rome and Catania, Italy
}

\begin{abstract}
SUMMARY
To evaluate the efficacy of Mipragoside, a ganglioside derivative, in vernal keratoconjunctivitis we performed a controlled randomised clinical trial involving 24 patients (mean age $10 \pm 3.4$ years, range 5-20 years). Patients received either Mipragoside $0.5 \%$ aqueous ophthalmic gel or placebo four times a day for 2 weeks after a week of treatment with placebo. Ocular signs and symptoms were evaluated and considered for statistical analysis. Results show that Mipragoside significantly reduces all symptoms, being most effective on itching $(p=0.01 ; \quad p=0.0001)$ and hyperaemia $(p=0.01 ; p=0.0006)$ after 1 and 2 weeks respectively when compared with placebo. Physician judgement of drug efficacy at the end of treatment was significantly in favour of Mipragoside $(p=0.0001)$ compared with placebo. We conclude that Mipragoside topical treatment improves symptoms of patients with vernal keratoconjunctivitis and we postulate a possible antiinflammatory activity of this compound.
\end{abstract}

Mipragoside (molecular weight 1574) is the isopropylic ester of a monosialotetrahexosyl ganglioside $\left(\mathrm{GM}_{1}\right)$, a natural ganglioside. Gangliosides are complex biological molecules which consist of a short carbohydrate chain with one or more sialic acid residues attached to a double lyphophilic tail formed by the aminoalcohol sphingosin and a fatty acid. These substances are natural components of the outer surface of the cell membrane, particularly abundant in the nervous system. Exogenously administered, gangliosides have been shown to enhance recovery after central nervous system injury. ${ }^{1}$ Recent studies suggest that the esterification of $\mathrm{GM}_{1}$, through which Mipragoside is obtained,

From: ${ }^{1}$ Department of Ophthalmology, University of Rome 'Tor Vergata', Rome, Italy; ${ }^{2}$ Fidia Sud Eye Research Division, Catania, Italy.

Correspondence to: Marco Centofanti, MD, Università degli Studi di Roma 'Tor Vergata', Clinica Oculistica, Complesso Integrato Columbus, Via della Pineta Sacchetti 506, I-00168 Rome, Italy. provides the molecule with marked anti-inflammatory and analgesic activity due to its anti-exudative capacity. ${ }^{2}$ In vitro, Mipragoside inhibits histamine release from human basophils and rat mast cells following allergen stimulation. ${ }^{3}$ Moreover, treatment with Mipragoside ophthalmic gel significantly reduced the number of conjunctival eosinophils following ocular challenge with 48/80 in the rabbit. ${ }^{4}$ In humans topical application of Mipragoside ophthalmic gel significantly reduced the inflammatory cell recruitment in the tear fluid following specific allergen challenge in patients with ocular hay fever. ${ }^{5}$

Vernal keratoconjunctivitis (VKC) is a chronic and recurrent ocular disease characterised by a marked cellular inflammatory infiltration in which mast cells, eosinophils, lymphocytes and basophils, as well as their derived soluble mediators, have a major pathogenetic role. ${ }^{6}$

The purpose of the study was to investigate in a double-masked randomised study whether Mipragoside $0.5 \%$ ophthalmic gel is effective in the treatment of $\mathrm{VKC}$ when compared with placebo.

\section{MATERIALS AND METHODS}

A double-masked randomised study was performed in 24 ( 21 male, 3 female) patients with a history of VKC (Table I). Their mean age was $10 \pm 3.5$ years, range 5-20 years. Diagnosis was based on clinical examination, history of seasonal exacerbation of the disease and the presence of eosinophils in a conjunctival scrape. All patients had only the palpebral and not the limbal form of VKC. Only 2 patients had giant papillae in their upper tarsal conjunctiva.

The following ocular signs and symptoms were considered: itching, burning, photophobia, grittiness, discharge, tearing and hyperaemia. Each sign and symptom was evaluated and scored from 0 to $4^{+}$as follows: 0 , absent; $1^{+}$, mild $; 2^{+}$, moderate; $3^{+}$, severe; 
Table I. Demographic characteristics of patients

\begin{tabular}{lcc}
\hline & Mipragoside group & Placebo group \\
\hline Total no. of patients enrolled & 12 & 12 \\
Age (years \pm SD) & $10 \pm 3.01$ & $10 \pm 3.96$ \\
Sex (M/F) & $10 / 2$ & $11 / 1$ \\
Total no. of patients eligible for statistical analysis & 11 & 9 \\
Age (years \pm SD) & $9 \pm 3.14$ & $10 \pm 4.18$ \\
Sex (M/F) & $9 / 2$ & $8 / 1$ \\
Duration of disease (months) (means \pm SD) & $35 \pm 29.5$ & $42 \pm 28.2$ \\
\hline
\end{tabular}

$4^{+}$, very severe. A minimum score of $8^{+}\left(\right.$or $4^{+}$with at least $2^{+}$for itching) was required for a patient to enter the trial.

Patients who had other eye diseases, wore contact lens or were taking other anti-inflammatory therapies were excluded from the study. No other topical medications were allowed during the trial and all patients were without topical medication for at least 1 week before the beginning of the study. Formal consent was obtained from all patients or their parents before starting the treatment.

Each patient received either Mipragoside 0.5\% ophthalmic gel (Mipragoside, sorbitol, carboxypolymethylene, purified water, sodium hydroxide qs to $\mathrm{pH}$ 6.5; manufactured by. Fidia, Abano Terme, Italy) or placebo (the same compounds without Mipragoside) unidose, 4 times a day for 2 weeks. All patients had a week of washout with placebo before the treatment. Clinical signs and symptoms were assessed at entry, after the baseline week and after 1 and 2 weeks of treatment. An overall assessment at the end of treatment was performed by the clinicians in the study and graded from 1 (fully controlled) to 7 (worse).

Non-parametric (Mann-Whitney $U$-test and Kruskal-Wallis test) statistical analysis was performed. A probability of 0.05 or less was considered statistically significant.

\section{RESULTS}

Twenty patients (11 treated with Mipragoside $0.5 \%$ ophthalmic gel and 9 with placebo) completed the clinical trial and were considered for statistical analysis (Table I). Four patients withdrew from the study; 3 patients ( 2 in the placebo group and 1 in the Mipragoside group) for non-cooperation and 1 patient (placebo group) for treatment failure. The total mean score at the end of baseline was $10.8 \pm 3.7$ for patients in Mipragoside group and 13.5 \pm 3.7 for the control group. A statistically significant difference was observed between treatment and placebo groups at the end of baseline for oedema $(p=0.01)$, burning $(p=0.05)$ and photophobia $(p=0.05)$. These parameters have not been included in the statistical analysis. After 7 days of treatment Mipragoside significantly reduced hyperaemia $(p=0.01)$ (Table II), itching $(p=0.01)$ (Table II) and grittiness $(p=0.0001)$ compared with the placebo. At the end of treatment (14 days), Mipragoside significantly reduced hyperaemia $(p=0.0006)$ (Table II), itching $(p=0.0001) \quad$ (Table II), grittiness $(p=0.001)$, discharge $(p=0.01)$ and tearing $(p=0.0001)$ compared with the placebo. No statistical differences were observed for any symptom between the time of entry into the study and the end of the baseline period (day 0 ).

According to the clinicians involved, Mipragoside produced a marked improvement in the overall condition of 10 patients (91\%) and a little improvement in 1 patient $(9 \%)$, while in the placebo group a mild clinical improvement was observed in 6 patients $(69 \%)$ and no change in 3 patients $(33 \%)$. The difference between groups was statistically significant $(p<0.0001)$.

\section{DISCUSSION}

Our study shows that Mipragoside is more effective than placebo in reducing the ocular signs and symptoms of patients with mild to moderate VKC.

Gangliosides are components of all cell membranes and are particularly abundant in the nervous system, where they induce neurogenesis and exhibit a trophic effect on nerve cell growth in vitro. In vivo, a particular ganglioside, $\mathrm{GM}_{1}$, reduces cerebral oedema and accelerates recovery from injury to the peripheral and central nervous system. ${ }^{1}$ Gangliosides are potent immunomodulatory agents capable of

Table II. Frequency distribution of hyperaemia and itching scores in the two treatment groups

\begin{tabular}{|c|c|c|c|c|c|c|c|c|c|c|c|c|c|}
\hline \multirow[b]{2}{*}{ Treatment day } & \multirow[b]{2}{*}{ Treatment group } & \multicolumn{5}{|c|}{ Hyperaemia score } & \multirow{2}{*}{$\begin{array}{c}\text { Mean } \\
\text { hyperaemia score }\end{array}$} & \multicolumn{5}{|c|}{ Itching score } & \multirow{2}{*}{$\begin{array}{l}\text { Mean itching } \\
\text { score }\end{array}$} \\
\hline & & 0 & $1^{+}$ & $2^{+}$ & $3^{+}$ & $4^{+}$ & & 0 & $1^{+}$ & $2^{+}$ & $3^{+}$ & $4^{+}$ & \\
\hline \multirow[t]{2}{*}{ Day 0} & Mipragoside & & & 4 & 7 & & $2.6 \pm 0.5$ & & 2 & 8 & 1 & & $1.9 \pm 0.5$ \\
\hline & Placebo & & 1 & 4 & 4 & & $2.3 \pm 0.7$ & & 2 & 6 & 1 & & $1.8 \pm 0.5$ \\
\hline \multirow[t]{2}{*}{ Day 7} & Mipragoside & 1 & 8 & 2 & & & $1.0 \pm 0.5 *$ & 2 & 9 & & & & $0.8 \pm 0.4 *$ \\
\hline & Placebo & & 5 & & 4 & & $1.8 \pm 1.0$ & 1 & 4 & 4 & & & $1.3 \pm 0.7$ \\
\hline \multirow[t]{2}{*}{ Day 14} & Mipragoside & 5 & 6 & & & & $0.5 \pm 0.5 * *$ & 10 & 1 & & & & $0.1 \pm 0.3 * * *$ \\
\hline & Placebo & 1 & 4 & 2 & & 2 & $1.7 \pm 1.3$ & 1 & 5 & 1 & 1 & 1 & $1.5 \pm 1.0$ \\
\hline
\end{tabular}

${ }^{*} p=0.01$ vs placebo; ${ }^{* *} p=0.0006$ vs placebo; ${ }^{* * *} p=0.0001$ vs placebo. 
inhibiting the mitogenic activation of lymphocytes or the stimulatory action of interleukin-2 in vitro. ${ }^{7-9}$ Moreover, gangliosides have an inhibitory action on cells and inflammatory mediators in both experimental animals and humans. ${ }^{2,3}$ Although their mechanism of action in extraneuronal cells has not been defined, it seems likely that it is due to activation of phospholipase $\mathrm{C}$, which leads to the generation of inositol-1,4,5-triphosphate and diacylglycerol and an elevation of intracellular $\mathrm{Ca}^{2+}$. A rise in the intracellular concentration of $\mathrm{Ca}^{2+}$ serves to initiate exocytosis with a mechanism that probably involves the activation of $\mathrm{Ca}^{2+} /$ calmodulin-dependent protein kinases and protein kinase $C^{4}$ Recent studies have shown that Mipragoside acts by stabilising mast cell membranes, probably because it interferes ${ }^{2}$ with the transmembranous calcium fluxes.

The presence of inflammatory cells and mediators is a constant feature of VKC. Mast cells, eosinophils, neutrophils and lymphocytes infiltrate the conjunctival mucosa and have an active role in the allergic inflammation. ${ }^{6}$ The efficacy of topical Mipragoside on the ocular signs and symptoms of patients with $\mathrm{VKC}$ could be due to an anti-inflammatory action on cells and mediators of this disease.

In conclusion, Mipragoside ophthalmic gel seems to be effective in the treatment of VKC and could be a valid therapeutic alternative to sodium cromoglycate.
Key words: Mipragoside, Vernal keratoconjunctivitis, Children, Young adults, Controlled clinical trial.

\section{REFERENCES}

1. Rodden FA, Wiegandt H, Bauer BL. Gangliosides: the relevance of current research to neurosurgery. $J$ Neurosurg 1991;74:606-19.

2. Amico Roxas M, Caruso A, Cutuli VMC, Scapagnini U, Morandi A. Anti-inflammatory action of $\mathrm{AGF}_{44}$, a gangliosides ester derivative. Drugs Exp Clin Res 1992;18:251-9.

3. Jensen C, Svendsen UG, Thastrup O, Stahl Skov P, Leon A, Norn S. Complexity of the influence of gangliosides on histamine release from human basophils and rat mast cells. Agents Action 1987;21:79-82.

4. Bucolo C, Campana G, Spadaro A, Mangiafico S. Effects of Mipragoside on ocular allergic inflammation in the rabbit. J Ocul Pharmacol 1993;9:321-32.

5. Bonini St, Centofanti M, Schiavone M, Magrini L, Pocobelli D, Pierdomenico R, Bonini Se. Inhibition of conjunctival allergen challenge by topical Mipragoside. Invest Ophthalmol Vis Sci 1992;33:997.

6. Tomassini M, Magrini L, Bonini S, Lambiase A, Bonini $\mathrm{S}$. Increased serum levels of eosinophil cationic protein and eosinophil-derived neurotoxin (Protein X) in vernal keratoconjunctivitis. Ophthalmology 1994;101:1808-11.

7. Marcus DM. A review of the immunogenic and immunomodulatory properties of glycosphingolipids. Mol Immunol 1984;21:1083-91.

8. Krishnaraj R, Lin J, Kemp RG. Lectin and ionophore stimulated $\mathrm{Ca}^{++}$influx in murine lymphocytes: inhibition by disialoganglioside. Cell Immunol 1983;78:152-60.

9. Parker J, Caldini G, Krishnamurti C, Arens PB, Ankel $\mathrm{H}$. Binding of interleukin 2 to gangliosides. FEBS Lett 1984;170:391-5. 